JIOM Nepal, Volume 41, Number 2, August 2019, page 40-44

\title{
Ventilator-Associated Pneumonia in Neurosurgical Patients: A Tertiary Care Center Study
}

\author{
'Dipendra K Shrestha, 'Binod Rajbhandari, 'Amit Pradhanang, 'Gopal Sedain, 'Sushil K Shilpakar, \\ ${ }^{2}$ Saurav Pradhan \\ 'Department of Neurosurgery, Maharajgunj Medical Campus, Tribhuvan University Teaching Hospital, Institute of \\ Medicine, Maharajgunj, Kathmandu, Nepal \\ ${ }^{2}$ Department of Anesthesiology, Maharajgunj Medical Campus, Tribhuvan University Teaching Hospital, Institute of \\ Medicine, Maharajgunj, Kathmandu, Nepal
}

\section{Corresponding author:}

Dipendra K Shrestha, MBBS, MS

Department of Neurosurgery, Maharajgunj Medical Campus, Tribhuvan University Teaching Hospital, Institute of Medicine, Maharajgunj, Kathmandu, Nepal

Email:dipensk@gmail.com

Submitted: May 24, 2019

Accepted : Jul 4, 2019

\begin{abstract}
Introduction

Ventilator-associated pneumonia (VAP) is a well recognized complication in patients who are admitted to the Intensive Care Unit (ICU). A number of factors have been suspected or identified to increase the risk of VAP in Neurosurgical patients. Early and rapid diagnosis and initiation of the appropriate antibiotic treatment reduce mortality and decrease the development of MDR organisms. The aim of our study is to determine the incidence of VAP in the neurosurgical patients and also to assess the probable contributing neurosurgical risk factors and find out the causative bacterial pathogens and the resistant pattern of these bacteria in neurosurgical patient in ICU of our institute
\end{abstract}

\section{Methods}

A retrospective observational study of 106 neurosurgical patients who were on mechanical ventilation for more than 48 hours was done.

\section{Results}

Out of 106 patients, 35 patients fulfilled the clinical and microbiological criteria for the diagnosis of VAP. The commonest age group involved was between 15-25 years of age with male preponderance. Head injury was the commonest etiology. There was a linear correlation between the number of days in ICU and the development of VAP. The majority of the pathogen isolated were gram-negative bacteria and all were sensitive to Colistin.

\section{Conclusion}

Head injury is a significant risk factor for VAP. Prolonged mechanical ventilation is an important risk factor for VAP.

Keywords: Intensive care unit, neurosurgical patient, ventilator-associated pneumonia

\section{INTRODUCTION}

V entilator-associated pneumonia (VAP) is defined as pneumonia that occurs more than 48 hours after endotracheal intubation or tracheostomy. It is a well-recognized complication in patients who are admitted to the Intensive Care Unit (ICU), caused by infectious agents not present or incubating at the time mechanical ventilation (MV) is started. ${ }^{1}$ Generally, it occurs in $9-24 \%$ of patients intubated for longer than 48 hours. This infection can be classified into early onset (within the first 96 hours of MV) and late onset (more than 96 hours after the initiation of MV). ${ }^{2}$ The latter is more commonly attributable to multidrug-resistant (MDR) pathogens. These deadly pathogens, also known as "superbugs" can cause significant morbidity and mortality. With infection caused by such bacteria, the death rate may be as high as $20-30 \%$ in critically-ill ICU patients who have undergone invasive MV via an endotracheal tube (ETT) or tracheostomy. European Centre for Disease Control (ECDC) and Centre for Disease Control and Prevention (CDC), Atlanta, USA, have elaborately defined the standardized international terminologies, such as the multidrug-resistant (MDR), extensively 
Table 1. Organism isolated from neurosurgical patients with VAP

\begin{tabular}{lcc}
\hline \multicolumn{1}{c}{ Microorganisms } & Frequency & Percent \\
\hline Gram negative & & \\
Klebsiella pneumoniae & 19 & 54.3 \\
Acinetobacter & 12 & 34.3 \\
Pseudomonas aeruginosa & 3 & 8.6 \\
Citrobacter & 1 & 2.9 \\
Burkholderia & 1 & 2.9 \\
Gram-positive & & \\
Staphylococcus aureus & 1 & 2.9 \\
\hline
\end{tabular}

drug-resistant (XDR), and pan drug-resistant (PDR) bacteria. ${ }^{3}$ The rate of VAP ranges from $4-14 / 1000$ ventilator days in the United States and 10-52.7/1000 days in the developing countries. ${ }^{4}$

A number of factors have been suspected or identified to increase the risk of VAP in various studies. A higher incidence of VAP in neurosurgical patient has also been reported in patients with traumatic head injury as compared to the other ICU patients. However, some studies have reported high association of VAP in patients who have suffered from subarachnoid hemorrhage (SAH). ${ }^{5}$ Other risk factors in neurosurgical patients for the development of early VAP include the use of barbiturates, continuous sedation, intracranial hypertension, and delayed enteral feeding. To achieve better results, early and rapid diagnosis and initiation of the appropriate antibiotic treatment is essential in cases with VAP. Various studies have shown that the delayed administration of appropriate antibiotic therapy in the VAP patients has been associated with excess hospital mortality. ${ }^{6}$ Nosocomial bacterial pneumonia continues to complicate the course of 7 - $41 \%$ of patients receiving continuous MV despite major advances in techniques and the routine use of efficient disinfection procedures for the respiratory equipment. ${ }^{7}$

Therefore, knowledge of the incidence of VAP, associated risk factors and common pathogens causing VAP can help in development of effective preventive measures and bundle protocols, which in turn will decrease the mortality and morbidity, duration of treatment and hospital stay. The aim of our study is to determine the incidence of VAP in the neurosurgical patients and also to assess the probable contributing neurosurgical risk factors, such as the site and nature of lesion in brain, mortality associated with VAP and find out the causative bacterial pathogens and the resistant pattern of these bacteria in neurosurgical patient in ICU of our institute.

\section{METHODS}

A retrospective observational study was conducted in the Department of Neurosurgery combined
Table 2. Multidrug Resistant (MDR) and Extensively Drug Resistant (XDR) bacteria isolated from VAP cases

\begin{tabular}{lcc}
\hline \multicolumn{1}{c}{ Microorganisms } & MDR (\%) & XDR (\%) \\
\hline Gram negative & & \\
Klebsiella pneumoniae & 66.7 & 50 \\
Acinetobacter & 33.3 & 35 \\
Pseudomonas aeruginosa & 0 & 10 \\
Citrobacter & 0 & 5 \\
Burkholderia & 0 & 0 \\
Gram-positive & & \\
$\quad$ Staphylococcus aureus & 2.9 & 0 \\
\hline
\end{tabular}

with Department of Critical Care Medicine in Tribhuvan University Teaching Hospital, Institute of Medicine, Maharajgunj Medical Campus, Kathmandu, Nepal. The medical records of patients admitted in ICU within a period of one year from August of 2017 to July of 2018 was thoroughly scrutinized. Those ICU patients who received MV for more than 48 hours were included in our study. The demographic profile of the neurosurgical patients, including name, age, sex, underlying clinical condition, date of admission to the ICU, history of previous antibiotic intake, the treatment being administered in the ICU and the clinical outcome of each patient were noted. Patients who were already on ventilation before admission to the ICU or those who died within 48 hours were excluded. Endotracheal aspirate (ETA) sample reports of all patients admitted in the ICU requiring MV for more than 48 hours were also careful studied. The diagnosis of VAP was made on the basis of the standard clinical and microbiological criteria. Statistical analysis was performed using Fisher's exact test and $p$-value $<0.05$ was considered statistically significant.

\section{RESULTS}

A retrospective study was conducted in our institution from August of 2017 to July of 2018. According to hospital medical records, a total of 148 neurosurgical patients were admitted in ICU in one year. Out of which, 106 patients $(71.6 \%)$ were on mechanical ventilation for more than 48 hours. On scrutinizing, only 35 patients fulfilled the clinical and microbiological criteria for the diagnosis of VAP. The incidence of VAP in our study was 33\% (35/106). Among the 35 patients who developed VAP, the incidence of VAP was highest among patients aged between $15-25$ years of age (25.7\%). The incidence of VAP was more among males 23 (65.7\%).

Trauma was the most common underlying factor (Table 4). Patients admitted to the ICU after trauma were at the highest risk of developing VAP with $45.7 \%$ of patients developing pneumonia. Out of the 35 cases, $22(62.9 \%)$ were categorized under early- onset VAP group and $13(37.1 \%)$ under the lateonset VAP group. Klebseilla was the most common causative organism found in both early- and late- 
Table 3. Antibiotic sensitivity pattern in Gram-negative organisms

\begin{tabular}{lccc}
\hline Microorganism & $\begin{array}{c}\text { Polymixin/ } \\
\text { Colistin }\end{array}$ & $\begin{array}{c}\text { Imipenem/ } \\
\text { Meropenem }\end{array}$ & $\begin{array}{c}\text { Piperacillin/ } \\
\text { Tazobactam }\end{array}$ \\
\hline Klebsiella & 12 & 3 & 2 \\
Acinetobacter & 8 & 4 & 1 \\
Pseudomonas & 2 & 1 & 0 \\
Citrobacter & 1 & 0 & 0 \\
\multicolumn{2}{c}{ Total 23(65.7\%) } & 8(22.9\%) & 3 (8.6\%) \\
\hline
\end{tabular}

\section{onset VAP}

The incidence of VAP increased in patients who were on MV for 10 or more days $(77.1 \%)$ as compared to those who were ventilated for less than 10 days $(22.9 \%)$ [ $<<0.006$ ]. A total of 15 patients $(42.9 \%)$ underwent tracheostomy. Among them, 6 patients underwent an early ( $\leq 10$ days), and 9 patients underwent late (>10 days) tracheostomies. Patients who underwent an early tracheostomy had a mean MV duration and ICU stay of $18.3 \pm 16.3$ and 24.0 \pm 15.2 days, respectively as compared to $28.0 \pm$ 19.1 and $31.0 \pm 16.6$ days, respectively, in patients who underwent a late tracheostomy. It was seen that patients with an early tracheostomy had lesser duration of MV and an early weaning from the ventilator, hence, a shorter duration of ICU stay as compared to patients who underwent a late tracheostomy.

Out of the total 35 cases of VAP, $37.1 \%$ of cases had polymicrobial growth on culture; and $48.6 \%$ were monomicrobial. The majority of bacteria were gramnegative bacilli and gram-positive bacteria, such as staphylococcus aureus were less common. Among gram negative bacteria, klebsiella pneumonia is the most common pathogen to isolated. (Table 1)

Among 35 patients with VAP, 57.1\% and $8.6 \%$ of patient were positive for Extensively drug resistant (XDR) and Multidrug resistant (MDR) strains, respectively. Whereas Klebsiellapneumoniae strains are the commonest bacteria isolated for MDR and XDR, respectively as shown in table 2. Where as there is no resistant seen with Burkholderia. All Gram-negative bacterial strains were sensitive to
Colistin; whereas Gram-positive bacterial strains were sensitive to Co-trimoxazole.

While analyzing the development of VAP in relation to the underlying neurosurgical condition, VAP was more common in patients with trauma, especially in head injury $(45.7 \%)$, followed by spine injury in $20 \%$ of the VAP cases. $17.1 \%$ of cases was reported to be spontaneous SAH. Similarly, posterior fossa surgeries were found to have a little higher incidence rate of $5.7 \%$ of VAP as compared to meningioma (2.9\%). 8.6\% were Miscellaneous i.e brain abscess, TB meningitis with hydrocephalus.

With regard to the site, among a total of 35 VAPpositive patients, the supratentorial compartment etiologies (71.4\%) had a higher incidence as compared to the infratentorial compartment etiologies (8.6\%) and those at the pathologies of the craniovertebral junction and the cervical spine trauma (20\%). This observation again was found to be clinically significant.

According to the ICU mortality records, there were a total of 14 deaths among VAP cases. The overall mortality rate associated with VAP was observed to be $40 \%$ (14/35). It was highest in the age group of $>55$ years and lowest in age group of $15-25$ years of age.

\section{DISCUSSION}

In our study, 35 cases developed VAP in 106 neurosurgical patients on mechanical ventilation (33\%). This finding corroborates with previously published results. ${ }^{8}$ Head injury patients are at increased risk for VAP compared to medical patients. ${ }^{9}$ Similarly, in our study, we observed that head injury case was the most common underlying condition $(45.7 \%)$ followed by pathologies of the craniovertebral junction and the cervical spine trauma. We observe that $17.1 \%$ of VAP cases were aneurysmal SAH. Patients undergoing aneurysmal surgery have an increased likelihood of developing SIRS with the reported incidence ranging from 29 - 87\%. Immunosuppression has been found to be associated with a higher incidence of pneumonia in symptomatic aneurysmal SAH patients. SIRS

Table 3. VAP Incidence in neurosurgical patients based on age and underlying clinical condition

\begin{tabular}{|c|c|c|c|c|c|c|c|}
\hline \multirow{2}{*}{$\begin{array}{l}\text { Underlying } \\
\text { clinical condition }\end{array}$} & \multirow{2}{*}{ Frequency } & \multicolumn{5}{|c|}{ Patient developing VAP in different age group (\%) } & \multirow{2}{*}{$\begin{array}{c}\text { Total } \\
\text { percent }\end{array}$} \\
\hline & & $15-25$ & $26-35$ & $36-45$ & $46-55$ & $>55$ & \\
\hline Trauma (head injury) & 16 & 62.5 & 42.9 & 40.0 & 62.5 & 14.3 & 45.7 \\
\hline Spine injury & 7 & 12.5 & 28.6 & 20.0 & 12.5 & 28.6 & 20.0 \\
\hline Aneurysmal SAH & 6 & 0.0 & 0.0 & 0.0 & 25.0 & 57.1 & 17.1 \\
\hline Miscellaneous & 3 & 0.0 & 28.6 & 20.0 & 0.0 & 0.0 & 8.6 \\
\hline P-fossa tumor & 2 & 12.5 & 0.0 & 20.0 & 0.0 & 0.0 & 5.7 \\
\hline Pituitary and suprasellar region & 1 & 12.5 & 0.0 & 0.0 & 0.0 & 0.0 & 2.9 \\
\hline Total & 35 & 100.0 & 100.0 & 100.0 & 100.0 & 100.0 & 100.0 \\
\hline
\end{tabular}


often contributes to the acute lung injury and a poor outcome after SAH. ${ }^{10}$

Regarding the site, contrary to the prevalent belief of the patients with an infratentorial compartment lesion having a higher incidence of VAP, our study found that patients with a supratentorial compartment pathology had a higher incidence $(71.4 \%)$ of VAP. Another risk factor, which was evaluated in this study was the duration of mechanical ventilation and its association with VAP. We observed that the incidence of VAP increased in patients who were on mechanical ventilation for more than 10 days (85.2\%) as compared to those who were ventilated for less than 10 days $(50 \%$ [p < 0.01]). Thus, the incidence of VAP increases with the duration of mechanical ventilation. These findings were similar to an Italian study that included 724 ICU patients and showed that the incidence of VAP increased from $5 \%$ for patients receiving MV for 1 day to $69 \%$ receiving ventilation for $\geq 30$ days. ${ }^{11}$ One more risk factor, prolonged antibiotic administration to ICU patients for the treatment of primary infection results in a "super infection", from the selection of and the subsequent colonization of resistant pathogens, which was evaluated in our study was the administration of broad spectrum antibiotics in the preceding 7 days. It was observed that out of the 35 patients who developed VAP, 9 $(25.7 \%)$ were on some broad spectrum antibiotics in preceding 5-7 days.

In our study Acinetobacter spp. (55.6\%) accounted for the highest number of cases followed by Klebseila. $(44.4 \%)$ these two pathogens were responsible for $25.7 \%$ VAP cases. Similar Study of VAP done in a French ICU they noted that prior antimicrobial therapy markedly increased the rate of VAP caused by $\mathrm{P}$. Aeruginosa and Acinetobacter spp. These two pathogens in their study accounted for $65 \%$ of VAP cases among patients who have previously received antibiotics, compared with only $19 \%$ of VAP cases among antibiotic-naïve patients. ${ }^{12}$ Similarly, Joseph et al. also reported Acinetobacter spp. and $P$. Aeruginosa as the predominant organisms causing VAP. ${ }^{13}$ Airway intubation is associated with increased frequency of Gram-negative bacterial colonization of upper and lower respiratory tract with subsequent overgrowth and pneumonia. Non fermenters such as Pseudomonas spp. and Acinetobacter were significantly associated with late onset VAP as observed by other workers. ${ }^{14}$ In our study Klebseila was the most common pathogen followed by Acinobactor species which are responsible for both the early onset and late onset VAP. Similar study done by Giantsou et al. also observed that potentially multiresistant P. Aeruginosa has been seen to be the most commonly isolated pathogen in both early onset and late onset VAP. ${ }^{15}$ Regarding the antibiotic sensitivity pattern, our results were in accordance with the study conducted. ${ }^{16}$ In gram-negative organisms that resistant to the commonly used antibiotics and showed sensitivity to the Colistin or the Imipenem group and for grampositive organisms our study showed a sensitivity to Cotrimoxazole.

Out of 35 patients with VAP, $57.1 \%$ and $8.6 \%$ of patients were positive for Extensively drug resistant (XDR) and Multidrug resistant (MDR) strains, respectively. The slightly increased incidence of drug resistant strains observed in our study may be because our hospital is a tertiary referral care center in a rural setup, cases with advanced diseases with Critically ill patient's referral from adjoining districts and even villages are admitted for treatment. Before attending the hospital, most of the patients get spectra of antibiotics from general practitioners or due to over-the-counter sell of antibiotics often in improper dose. Early detection and close monitoring of MDR, XDR, bacterial strains must be started by all clinical microbiology laboratories to reduce the menace of antimicrobial resistance which is now a global problem.VAP has been associated with a mortality rate between $24-76 \%$, observed at different institutions. Patients with VAP are estimated to have a 2-10 fold higher rate of mortality as compared to the ventilated patients without pneumonia. ${ }^{17}$ The overall mortality in patients with VAP in our study was $40 \%$. This figure is comparable to that of the study done by Mukhopadhyay et al. In which the overall mortality rate was $48.3 \%$ among patients with VAP. ${ }^{18}$

\section{CONCLUSION}

VAP is a serious problem in the ICU leading to a longer hospital stay and increased mortality and morbidity. Prolonged mechanical ventilation is an important risk factor. Further prospective larger studies addressing this important problem is warranted in future.

\section{CONFLICT OF INTEREST}

None declared.

\section{REFERENCES}

1. American Thoracic Society, Infectious Diseases Society of America. Guidelines for the Management of Adults with Hospital-acquired, Ventilator-associated, and Healthcare-associated Pneumonia. Am J RespirCrit Care Med. 2005 Feb 15;171(4):388-416.

2. Morehead RS, Pinto SJ. Ventilator-associated pneumonia. Arch Intern Med. 2000 Jul 10;160(13):192636.

3. Michael SN, Donald EC. American Thoracic Society, Infectious Diseases Society of America. Guidelines for the management of adults with hospital-acquired, ventilator-associated, and healthcare-associated pneumonia. Am J RespirCrit Care Med. 2005;171:388416.

4. Rodrigues DO, Cezário RC, GontijoFilho PP. VentilatorAssociated Pneumonia (VAP) caused by MultidrugResistant (MDR) Pseudomonas aeruginosa vs. other microorganisms at an adult clinical-surgical intensive 
care unit in a Brazilian University Hospital: Risk factors and outcomes. Int J Med Med Sci. 2009;1(10):432-7.

5. Cinotti R1, Dordonnat-Moynard A, Feuillet F, Roquilly A, Rondeau N, Lepelletier D, Caillon J, Asseray N, Blanloeil $Y$, Rozec B AK. Risk factors and pathogens involved in early ventilator-acquired pneumonia in patients with severe subarachnoid hemorrhage. - PubMed - NCBI. Eur J ClinMicrobiol Infect Dis. 2014;33(5):823-30.

6. Iregui $M$, Ward $S$, Sherman $G$, Fraser VJ, Kollef $\mathrm{MH}$. Clinical importance of delays in the initiation of appropriate antibiotic treatment for ventilatorassociated pneumonia. Chest. 2002;122:262-8.

7. Fagon JY, Chastre J, Domart Y, Trouillet JL, Pierre J, Darne $C$, et al. Nosocomial pneumonia in patients receiving continuous mechanical ventilation. Prospective analysis of 52 episodes with use of a protected specimen brush and quantitative culture techniques. Am Rev Respir Dis. 1989;139:877-84.

8. Morehead RS, Pinto SJ. Ventilator-associated pneumonia. Arch Intern Med. 2000;160:1926-36.

9. Cook DJ, Walter SD, Cook RJ, Griffith LE, Guyatt GH, Leasa $D$, et al. Incidence of and risk factors for ventilatorassociated pneumonia in critically ill patients. Ann Intern Med. 1998;129:433-40.

10. Wartenberg KE, Schmidt JM, Claassen J, Temes RE, Frontera TA, Ostapkovich $\mathrm{N}$, et al. Impact of medical complications on outcome after subarachnoid hemorrhage. Crit Care Med 2006;34:617-23

11. Langer M, Mosconi P, Cigada M, Mandelli M. Long-term respiratory support and risk of pneumonia in critically ill patients. Intensive Care Unit Group of Infection
Control. Am Rev Respir Dis. 1989;140:302-5.

12. Fagon JY, Chastre J, Domart Y, Trouillet JL, Pierre J, Darne $C$, et al. Nosocomial pneumonia in patients receiving continuous mechanical ventilation. Prospective analysis of 52 episodes with use of a protected specimen brush and quantitative culture techniques. Am Rev Respir Dis. 1989;139:877-84.

13. Joseph NM, Sistla S, Dutta TK, Badhe AS, Rasitha D, Parija SC. Ventilator-associated pneumonia in a tertiary care hospital in India: Role of multi-drug resistant pathogens. J Infect DevCtries. 2010;4:218-25.

14. Dey A, Bairy I. Incidence of multidrug-resistant organisms causing ventilator-associated pneumonia in a tertiary care hospital: A nine months' prospective study. Ann Thorac Med. 2007;2:52-7.

15. Giantsou E, Liratzopoulos N, Efraimidou E, Panopoulou M, Alepopoulou E, Kartali-Ktenidou S, et al. Both earlyonset and late-onset ventilator-associated pneumonia are caused mainly by potentially multiresistant bacteria. Intensive Care Med. 2005;31:1488-94.

16. Dhadke VN, Dhadke S, Bhoite V. To study VAP incidence, risk factors and outcome in patients on mechanical ventilation in medical intensive care unit. Int $\mathrm{J}$ Curr Res Aca Rev 2015;3:35-53.

17. 17. Chowdhury $D$, Duggal AK. Intensive care unit models: Do you want them to be open or closed? A critical review. Neurol India 2017;65:39-45.

18. Mukhopadhyay C, Bhargava A, Ayyagari A. Role ofmechanical ventilation and development of multidrug resistant organisms in hospital acquired pneumonia. Indian J Med Res. 2003;118:229-35. 